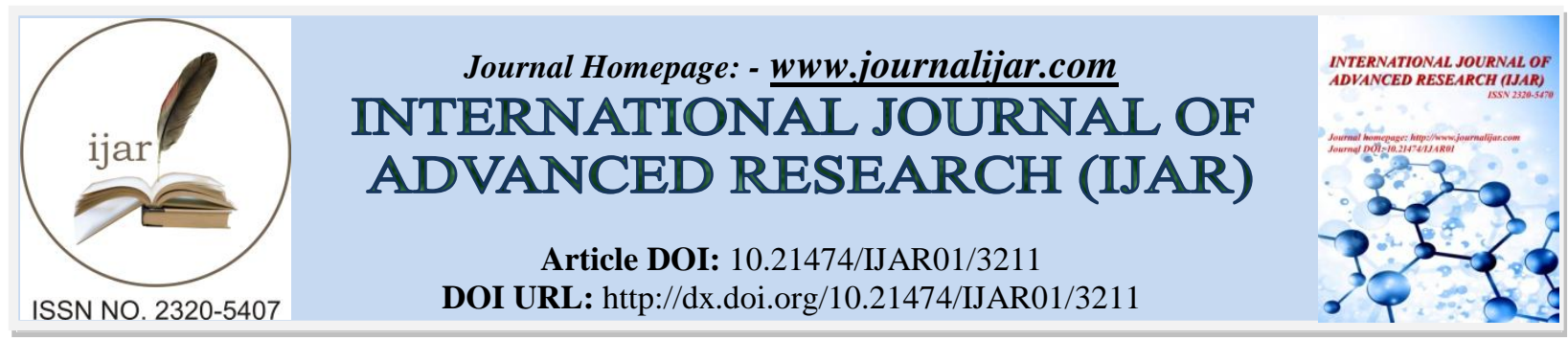

RESEARCH ARTICLE

\title{
DEVELOPMENT, PILOTING AND EVALUATION OF A FRAMEWORK FOR INCREASING UTILIZATION OF SKILLED MATERNAL HEALTHCARE SERVICES: STUDY IN SIAYA COUNTY
}

\section{Obinge Elizabeth Omondi ${ }^{1,3}$, Fred A. Amimo ${ }^{1}$ and Asito Stephen Amolo ${ }^{2}$.}

1. Department of Public Health, School of Health Sciences, Jaramogi Oginga Odinga University of Science and Technology.

2. Department of Biological Sciences, School of Biological and Physical Sciences, Jaramogi Oginga Odinga University of Science and Technology.

3. Department of Health, County Government of Siaya.

\section{Manuscript Info}

Manuscript History

Received: 18 December 2016

Final Accepted: 22 January 2017

Published: February 2017

Key words:-

Utilization, maternal health, antenatal care, skilled delivery, postnatal care and context specific framework.

\section{Abstract}

Utilization of skilled maternal healthcare services during pregnancy, delivery and post delivery can reduce maternal deaths from preventable conditions. However, despite the usefulness of utilizing the skilled maternal healthcare services, utilization has remained low in Siaya County while women continue to die from preventable conditions. The aim of this study was to identify the correlates of utilization of skilled maternal healthcare services in Siaya County and consequently develop, pilot and evaluate a context specific framework for increasing utilization of skilled maternal healthcare services in Siaya County.

Method:The study followed a three (3) phased approach, whereby baseline data was first collected from the study participants to ascertain their past maternal health services utilization experience ( antenatal, delivery and postnatal care services), followed by development and piloting of the framework which was informed by the findings of the baseline, and finally evaluation of the effectiveness of the framework. The framework was piloted through a longitudinal study involving 517 pregnant mothers with previous delivery experience from selected community health units in Siaya County. Statistical package for social sciences (SPSS) version 22 was used to analyze both descriptive and inferential statistics.

Result: Indicate that both community and health facility factors affect utilization of skilled maternal healthcare services. Compared to the baseline, $4^{\text {th }}$ Antenatal visits increased from $58.7 \%$ to $63.9 \%$, skilled deliveries from $55.7 \%$ to $64.6 \%$ and postnatal care services from $23.6 \%$ to $47.4 \%$. Knowledge on available maternal healthcare services and danger signs also increased by $28.6 \%$ and $26.4 \%$ respectively. Of note is that compared to the baseline, continuum of care was also enhanced as the number of households visited by community health volunteers (CHVs) increased from $83.7 \%$ to $93.5 \%$. an indication that there was increase in uptake of skilled maternal healthcare services.

Conclusion: The framework was effective in increasing utilization of skilled maternal healthcare services in Siaya County and will be useful in providing guidance on designing and integrating context specific 
Interventions for optimizing care continuum and increasing utilization of skilled maternal healthcare services in Siaya County.

Copy Right, IJAR, 2017,. All rights reserved.

\section{Introduction:-}

Globally, a woman dies every two minutes from complications related to childbirth (WHO, 2012). Of note, approximately 800 women die from preventable causes related to pregnancy and childbirth every day, with most of the deaths and disability occurring among women of reproductive age in the developing countries of the world (U. WHO, UNFPA, The World Bank and the United Nations Population Division, 2014). Previous studies have shown that a woman's lifetime risk of dying in pregnancy or childbirth is 1 in 150 in developing countries compared to 1 in 3800 in developed countries (WHO, 2012). This is partly due to inadequate utilization and poor quality maternal health care, antenatal care, skilled attendance at birth and postnatal care (W. Wang, Hong, Rathavuth, 2015; Zohra et al., 2015). Hence there is a need for women to maximize utilization of skilled maternal healthcare services (antenatal care, skilled attendance at birth and postnatal care) in order to prepare physically, mentally and even logistically for childbirth. Studies have shown that antenatal care is critical in improving maternal and neonatal health outcomes (W. Wang, Hong, Rathavuth, 2015; Zohra et al., 2015) through delivery of targeted interventions and use of emergency obstetric care services at the health facilities (W. Wang, Hong, Rathavuth, 2015).

The World Health Organization (WHO) recommends a minimum of four antenatal care visits, based on reviewing the effectiveness of different models of service delivery (Villar et al., 2001). WHO guidelines also specify the content of antenatal care visits, which should include blood pressure measurement, urine testing for bacteriuria and proteinuria, and blood testing to detect syphilis and severe anemia (WHO, UNFPA, The World Bank and the United Nations Population Division, 2014). Some other services, including giving tetanus immunization, providing iron and folate tablets and teaching women about danger signs of pregnancy complications, are also important to improve both maternal and newborn health (Wang et al., 2010). Access to skilled delivery care is key to reducing maternal mortality, particularly in sub-Saharan Africa, where 99\% of maternal deaths occur (WHO, UNFPA, WORLD BANK, 2012). Evidence suggests that skilled attendance at birth, access to emergency obstetric care and postnatal care are key factors in reducing the risk of maternal death, in both industrialized and developing countries (Graham, Moodley, \& Selipsky, 2012; Wang et al., 2010; WHO, ICM, \& FIGO, 2004). However, utilization of skilled attendance at birth in developing countries low with only $34 \%$ in the least developed countries delivering in a health facility providing skilled care (WHO, 2012). Compared to antenatal care and skilled attendance at birth, postnatal care has been largely neglected in safe motherhood programs in developing countries (Wang et al., 2010). Postnatal care, especially within the first 48 hours after birth, is critical to the management of postpartum hemorrhage, an important cause of maternal deaths in developing countries (Wang et al., 2010). Postnatal care is an important opportunity to assess the physical and psychosocial health of the mother and baby and has been shown to be a key strategy for reducing maternal mortality although the majority of women in developing countries do not receive it (Simkhada B, 2008;WHO, 2014).

Continuum of care throughout pregnancy, childbirth and postnatal period is also considered key in improving maternal and newborn health in order to reduce maternal and child morbidity and mortality (Siddharudha Shivalli, 2015; WHO, 2011). According to partnership for maternal, newborn and child health, 2011; Community Health Volunteers are important in identification of pregnant mothers and referrals, follow up and provision of community maternal health care services(WHO, 2011). Previous studies and reviews have showed that that community health workers are important in provision of a continuum of care for maternal and child health services(Gilmore B, 2013; Glenton C, 2013; Lewin S, 2010; Yeboah-Antwi et al., 2014). An effective continuum of maternal health care services that includes intervention packages from pre-pregnancy through to delivery and post delivery and from health facility to household has also been proven to be effective in improving the life of the mother and the baby (PMNCH, 2010; Annie and Carlo, 2003). Other studies have also shown that strengthened linkage between health facility and community enhances care continuum thus reducing morbidity and mortality (WHO, 2013). In limited resource settings, community-level interventions are also potentially effective to address the problem at its roots, as decisions to seek and access health care are strongly influenced by the socio cultural environment (John, Guadalupe and Stewart, 1999). Engagement of community health volunteers (CHWs) has proven to be effective in improving health status of the community (Beam \& Tessaro, 1994; Bhutta, Lassi, Pariyo, \& Huicho, 2010; Haines et al., 2007). 
Kenya is one of the Countries with high maternal mortality levels approximated at 495 per 100,000 live births (Kenya National Bureau of Statistics et al., 2015b), well above the MDG target of 147 per 100,000 by 2015 (Statistics, 2013). Kenya was rated among the top ten countries that contributed to 58\% of the global maternal deaths reported in 2013 (U. WHO, UNFPA, The World Bank and the United Nations Population Division., 2014), with over 6,000 women dying every year due to pregnancy related conditions despite the launch of Safe Motherhood campaigns twenty years ago (Macro, 2010; Starrs, 2006). In addition, it is estimated that another 20-30 women suffer serious injury or disability due to complications during pregnancy or delivery in Kenya (Human Rights., 2012). These high rates have persisted despite improvements in other health indicators over the past decades (Health, 2014). This problem is partly due to lack of access to skilled maternal health services, including ante-natal care, skilled delivery, and post-natal services (Health, 2014). Although there has been increased growth of health sector infrastructure, many women still face various barriers to accessing skilled maternal health services(Bourbonnais, 2013; Health, 2014; M. A. Pell C, Were F, Afrah NA, Chatio S, Manda-Taylor L, et al. (2013) 2013), This is attributed to supply-side and demand-side factors including individual and household factors, socio-cultural factors and health facility factors(Health, 2014; M. G. Kenya, 2010; M. o. H.-. Kenya, 2012). In Kenya there are major gaps and challenges associated with supply-side and demand-side factors leading to geographical disparities in coverage of health services between counties, urban and rural residents and different population groups(Kenya National Bureau of Statistics et al., 2015a). In attempt to address the identified challenges affecting uptake of skilled maternal healthcare services, the government of Kenya introduced community health strategy to empower individual and families to take responsibility for their health(Health, 2006) and also introduced a policy of free maternity services in all public facilities(Bourbonnais, 2013). As recommended by Kerber et al., 2007; the continuum of care for maternal, neonatal, and child health requires access to care provided by families and communities, by outpatient and outreach services, and by clinical services throughout the lifecycle, including adolescence, pregnancy, childbirth, the postnatal period, and childhood. Saving lives depends on high coverage and quality of integrated service-delivery packages throughout the continuum, with functional linkages between levels of care in the health system and between service-delivery packages, so that the care provided at each time and place contributes to the effectiveness of all the linked packages (Kerber et al., 2007).

While it is acknowledged that most causes of maternal deaths could be prevented through utilization of skilled maternal healthcare services (Graham et al., 2012; Wang et al., 2010; WHO et al., 2004); utilization of skilled maternal healthcare services have remained low in Kenya especially in counties like Siaya County despite massive investments on interventions to increase uptake of these services while mothers continue to die from preventable causes (DHIS 2014). Siaya County in Kenya is one of the counties with high MMR of 691 deaths for every 100,000 live births that is above the national average of 495 deaths for every 100,000 live births with most of these deaths occurring at home (MICS4 2011). Previous studies and reports in Siaya County associated the low uptake of skilled maternal healthcare services to poor communication between health workers and women, socio cultural beliefs, distance to health facilities and quality of ANC services (Pell et al., 2011: Bottleneck analysis 2012; Siaya investment case for $\mathrm{MNCH}$ 2013). However despite attempts to address the identified barriers, uptake of skilled maternal healthcare services has remained low (DHIS, 2014). The high maternal mortality ratio in Siaya County has been mainly attributed to low utilization of skilled maternal healthcare services (DHIS, 2014). Data indicate that the proportion of women attending at least one ANC visit are $85 \%$, those attending four ANC visits are $45 \%, 52 \%$ receive skilled care during delivery while only $30 \%$ receive postnatal care within two days after delivery (DHIS, 2014).

Different policies, frameworks and strategies have emerged to respond to the growing concerns on low utilization of skilled maternal healthcare services coupled with high maternal mortality levels in developing countries (Aday, 1974; Andersen, 1995; MOH, 2006; MOH, 2007: KNHSSP 11, 2005: WHO, 2006; MOH, 2014; WHO and PNMCH, 2011). However, despite massive investments in strategies to increase utilization of skilled maternal healthcare services and reduce maternal mortality, the gains have been very minimal (Siaya Health Department Performance Report 2013/14; Siaya County Integrated Development Plan, 2013 - 2017).

The use of community health workers in creating demand for skilled maternal health care services in Siaya County began in 2006 after the launch of the second Kenya national health sector strategic plan (KNHSSP 11). .However despite all the effort, Counties like Siaya County continue to have high maternal deaths (691/100,000 live births) above the national average of 495 deaths for every 100,000 live births, with most of these deaths being attributed to home deliveries and low utilization of skilled maternal healthcare services (Statistics, 2013). Previous studies done in Siaya County to establish factors affecting utilization of antenatal care services associated low uptake of antenatal 
care with uncertainty about pregnancy, poor communication between health workers and women, cultural and religious beliefs, vague knowledge and quality of ANC services among others (M. A. Pell C, Were F, Afrah NA, Chatio S, et al., 2013; UNICEF, 2013). However, the researcher could not trace any study related to uptake of skilled delivery and postnatal care services in Siaya County despite the worrying trend.

In the quest to increase utilization of skilled maternal health services in Siaya County, the health department managed to scale up implementations of key interventions such as provision of free maternity services, training of healthcare providers on focused antenatal care, $100 \%$ scale up of community healthcare services and payment of monthly stipend to all community health volunteers to motivate them to further intensify demand creation (Siaya, 2013; www.hiskenya.org, 2013/14). However despite the investments, utilization of skilled maternal healthcare has remained low; $4^{\text {th }}$ antenatal care- $45 \%$, skilled delivery $-52 \%$ and postnatal care- $30 \%$ (www.hiskenya.org, 2013/14) while mothers continue to die from preventable conditions. Taken together the above observation, the aim of this study was to develop and evaluate the effectiveness of context specific interventions to enhance maternal healthcare continuum and optimize utilization of skilled maternal healthcare services in Siaya County,

\section{Methods:-}

\section{Study design:-}

This was a longitudinal retrospective - prospective study conducted in 8 selected community units (CU) and their link health facilities in Siaya County. The baseline took 21/2 months, framework development 2 weeks and framework piloting/ intervention took 12 months from $27^{\text {th }}$ March 2015 to $27^{\text {th }}$ February 2016. The community health volunteers (CHVs) and the healthcare providers were sensitized on the study before commencement of the study and at every stage updated on the progress and their roles. The mothers were followed up by community health volunteers (CHVs) to ensure that they received all the recommended skilled maternal healthcare services which include $1^{\text {st }}$ to $4^{\text {th }}$ antenatal care visits, skilled delivery services and postnatal care services.

\section{Study setting:-}

Siaya County is one of the counties in Kenya located in the western region of the Country. It has six sub counties namely Ugenya, Ugunja, Gem, Siaya Alego, Rarieda and Bondo with an estimated population of 935,555 (KNBS, 2009). The county has sex-balanced ratio of female: male (52:48) with the population being predominantly youthful and 23 percent of the population is made up of women of reproductive age 205,356 (15-49). The estimated no of pregnant women is 37,592 and estimated deliveries is 37,592(www.hiskenya.org, 2013/14). The study was conducted in selected community Units and their link health facilities. The County has a total of 156 health facilities out of which 122 are government facilities. The County has 187 community units (an equivalent of a sub location) linked to the government health facilities and 2148 Community health volunteers (CHVs) who provide community based healthcare. Each community unit has approximately $10 \mathrm{CHVs}$ who manage about 100 households each. The study sites included Ndori community unit linked to Akala Health Center in Gem Sub County; Nyawita Community Unit linked to Nyawita dispensary in Bondo sub county; West Katweng'a Community Unit linked to Chianda Dispensary in Rarieda Sub County, Gongo community unit linked to Gongo Dispensary in Gem Sub county and Ulafu and Umala community unit linked to Umala dispensary in Alego Usonga sub county, Marenyo community Unit linked to Midhine dispensary and Yiro west community unit linked to Sikalame dispensary in Ugunja sub county. The term community unit referred to in this study is an equivalent of a sub location $(\mathrm{MOH}, 2010)$

\section{Study participants and recruitment:-}

A total of 517 pregnant mothers living within the selected community units were purposively recruited for the study. For purposes of knowing the previous maternal health services utilization status, only pregnant mothers who had had experience of giving birth previously (Not pregnant for the first time) were given the chance to participate. The participants were recruited through a combination of random and purposive sampling methodology. Some were invited to participate in the interview after being attended to at the link health facility; others were identified through snowballing technique and others through household's visitation.

\section{Sampling and sample size calculation:-}

The desired sample size was determined using the formula of Fisher et al 1991 as cited in Mugenda and Mugenda 2003: The target population was pregnant women in Siaya County while the accessible population was pregnant women from the selected community units. Since Siaya County has a population of 939,793(Siaya AWP3, 2014) and women of child bearing age form $23 \%=216,153$ (Siaya Annual Work Plan 3- 2014/15). The target population is pregnant women who account for $4 \%$ of the total population $=4 \%$ of $939,793=37592$ 


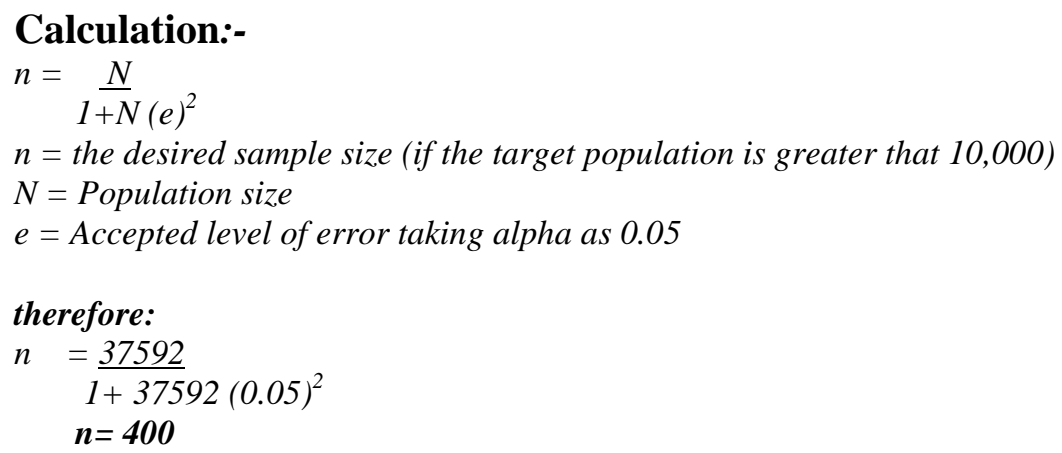

The sample size was increased by $20 \%$ to take care on non-response and fall outs. A final minimum sample size of 480 was obtained. However since the study was longitudinal with the likelihood of having fall out, all pregnant women who were willing to participate were enrolled for the study thus bringing the number to 517.

\section{Study sites:-}

The study sites were selected using multistage simple random sampling methodology. From a sampling frame of all community units per sub-county, one community unit was randomly picked from the list in each sub county and having calculated that each community unit would have approximately 50 pregnant mothers, for the study to achieve the recommended target of 400, an additional of 2 community units had to be selected randomly to be included. In total 517 sampled pregnant mothers who were willing to participate in the study were interviewed using structured questionnaires. All the questions were directed to the women's maternal health utilization experience in the previous pregnancy.

\section{Data Collection;-}

Data was collected using structured questionnaires focusing on the use of maternal healthcare services (antenatal care, skilled attendance at birth and postnatal care), participant's awareness and knowledge on maternal health, and continuum of care situation.

\section{Informed consent process:-}

Detailed information about the study was given to the participants by research assistants before being asked to decide on whether to participate or not. The consent was then read to the participant in the local language (Luo) after which those who accepted to participate were requested to sign. The study questionnaires and key informant interviews were administered thereafter.

\section{Data analysis:-}

The quantitative data was analyzed using both descriptive and inferential statistics. The descriptive statistics was used to describe and summarize the data inform of tables, frequencies and percentages. The inferential statistics was used to help make inferences and draw conclusions. Statistical tests including chi-square test, bivariate and multivariate logistic regression analysis was carried out to identify barriers associated with utilization of maternal health care services. All tests of significance was computed at $\alpha=0.05$. The Statistical Package for Social Sciences (SPSS) version 22 was used to analyze the data.

\section{Ethical consideration:-}

The study was approved by the ethical review board of University of East Africa Baraton (REC: $\mathrm{UEAB} / 05 / 02 / 2015)$.All the study participants parents and legal guardians gave their written informed consents.

\section{Results:-}

\section{Phase 1: Baseline findings}

Characteristics of Participants:-

As shown in table 1, most women (32.5\%) were aged between $15-19$ years, $72.5 \%$ were married and $39.1 \%$ were farmers. Most of the women and their partners or husbands had primary education $64 \%$ and $46 \%$ respectively while a majority $(57.3 \%)$ walked to the health facility. In addition for most $(38.7 \%)$ women it is their husbands who had authority over health issues. 
Table 1:- Summary of Socio-demographic characteristics of respondents ( $\mathrm{n}=517)$ and utilization of maternal healthcare services in Siaya County.

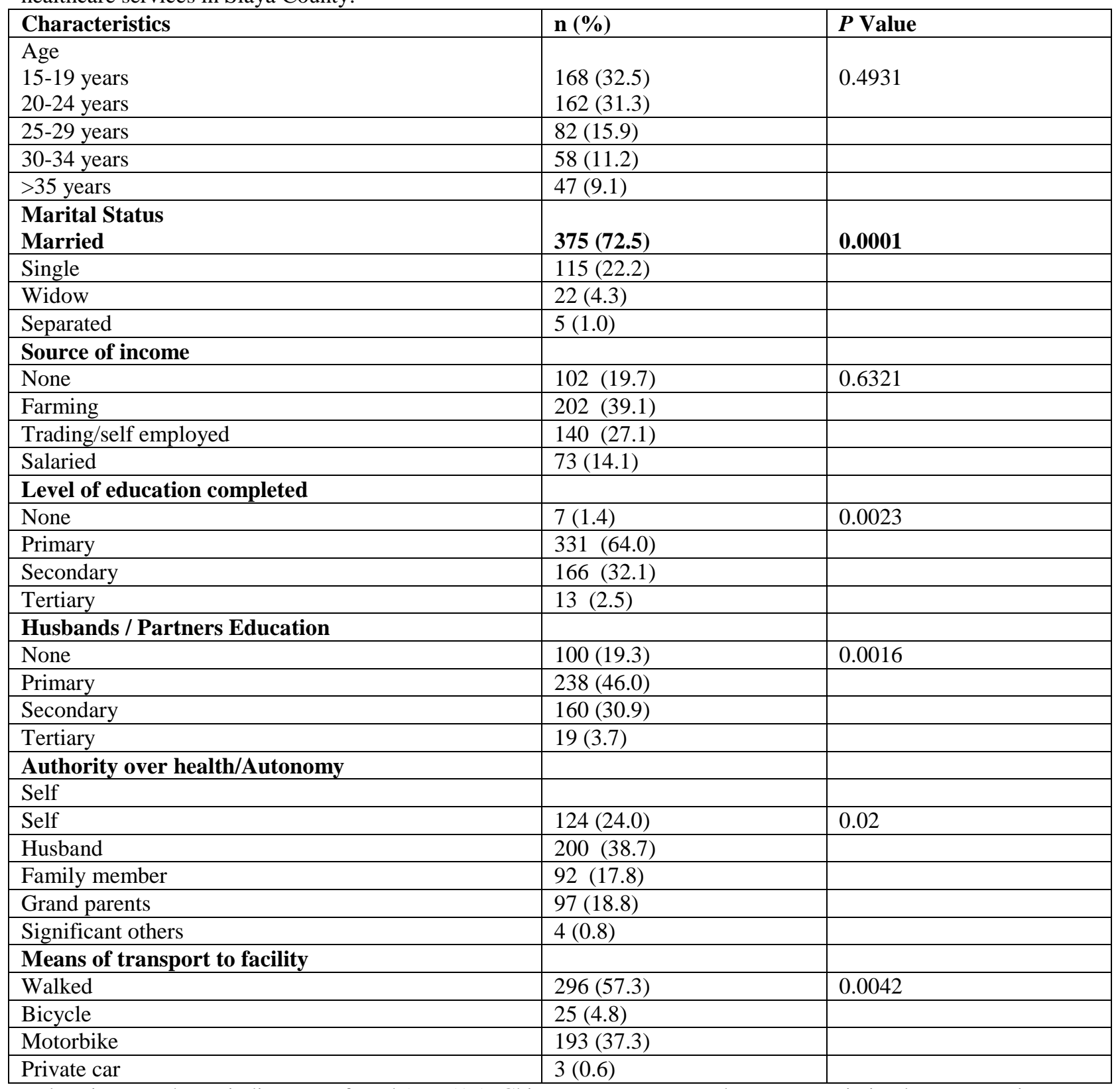

Values in parentheses indicate \% of total $(\mathrm{n}=517)$. Chi-square test was used to test association between sociodemographic characteristics and utilization of maternal health services and other group. Bold font indicates "significantly associated at $\mathrm{p}<0.05$.

History of utilization of skilled maternal health care services in the last pregnancy:-

Out of the 517 respondents, $439(84.9 \%)$ of the mothers received antenatal care (ANC) services, $288(55.7 \%)$ received skilled delivery while only 122 (23.6) received post-natal care. Out of the 517 respondents, 439 (84.9\%) of the mothers received Antenatal care (ANC) services while 15.1\% did not receive the ANC services. Out of those who received ANC services, 53.2\% received $\geq 4$ ANC visits while their counterpart's $46.9 \%$ received <4 ANC services. Moreover, out of the 288 (55.7\%) of the mothers who had Skilled delivery services; $47.7 \%$ of them had $<4 \mathrm{ANC}$ visits while $52.3 \%$ of the mothers had $\geq 4$ ANC visits. Again, out of $122(23.6 \%)$ of the mothers who managed to have Postpartum care services, $55.2 \%$ of them had $<4$ ANC visits while $44.8 \%$ of the mothers had $\geq 4$ ANC visits (Table 2). 
Table 2:- Previous skilled maternal healthcare services utilization history

\begin{tabular}{|l|l|l|l|l|}
\hline Maternal Health services & Total, $\mathbf{n}(\boldsymbol{\%})$ & $<$ 4ANC (\%) & $\mathbf{\geq}$ ANC (\%) & P value \\
\hline & & & & $\mathbf{0 . 0 0 3}$ \\
\hline Antenatal care (ANC) & $439(84.9)$ & 46.9 & 53.2 & \\
\hline Skilled delivery & $288(55.7)$ & 47.7 & 52.3 & \\
\hline Postpartum care & $122(23.6)$ & 55.2 & 44.8 & \\
\hline
\end{tabular}

Association between knowledge and utilization of skilled maternal health care services.

Knowledge plays a very important role in enhancing utilization of maternal health care services. Our data indicate that a majority of the respondents at $338(65.4 \%)$ had inadequate knowledge on maternal health services. Furthermore, a majority $(58.7 \%)$ of the respondents who were knowledgeable attended $\geq 4$ ANC. The findings revealed significant $(\mathrm{p}=0.007)$ association knowledge and utilization of ANC services. Out of 517 mothers who participated in the study, 55.9\% had adequate information on maternal health danger signs while $44.1 \%$ had inadequate. Out of the $55.9 \%$ of the mothers who had adequate information on danger signs; majority of them at $62.4 \%$ attended $\geq 4$ ANC visits. The findings further revealed that there is association between knowledge of danger signs and utilization of maternal health care services $(\mathrm{p}=0.001)$.

Table 3:- Knowledge and utilization of antenatal care services

\begin{tabular}{|l|l|l|l|l|}
\hline Characteristics & Total, $\mathrm{n}(\%)$ & $<4 \mathrm{ANC}(\%)$ & $\geq 4$ ANC (\%) & P value \\
\hline $\begin{array}{l}\text { Knowledge on importance of } \\
\text { maternal health services }\end{array}$ & & & & 0.007 \\
\hline Adequate & $179(34.6)$ & 41.3 & 58.7 & \\
\hline Inadequate & $338(65.4)$ & 58.1 & 41.9 & \\
\hline Information on danger signs & & & & 0.001 \\
\hline Adequate & $289(55.9)$ & 37.6 & 62.4 & \\
\hline Inadequate & $228(44.1)$ & 62.8 & 37.2 & \\
\hline
\end{tabular}

Participants profile and utilization of skilled maternal health services;-

Multivariate regression analysis revealed that those with no source of income (aOR=0.96, 95\% CI: 3.21-8.27) and those who were farmers $(\mathrm{aOR}=0.37,95 \% \mathrm{CI}: 7.32-6.74)$ were less likely to utilize maternal healthcare services relative to traders/self-employed and salaried. Further analysis showed that those with is secondary $(\mathrm{aOR}=2.62,95 \%$ CI: 4.33-4.58) and tertiary $(\mathrm{aOR}=1.43$, 95\% CI: 2.87-4.63) education were more likely to utilize maternal healthcare services relative to those with no education and those with primary education. Similarly, the respondents' whose husbands had no education $(\mathrm{aOR}=0.89,95 \% \mathrm{CI}: 2.07-1.60)$ or had primary education $(\mathrm{aOR}=0.89,95 \% \mathrm{CI}$ : 2.07-1.60) were less likely to utilize maternal healthcare services relative to those whose husbands had secondary or tertiary level of education. Those who walked $(0.91(1.62-2.88)$ or used bicycle $0.84(1.69-2.02)$ were less likely to utilize skilled maternal health services compared to those who used motorbike or private car. 
Table 5:- Factors associated with utilization of maternal health care Services

\begin{tabular}{|c|c|c|c|}
\hline Variables & Yes, n (\%) & $\begin{array}{l}\text { Unadjusted odds ratio } \\
(95 \% \mathrm{CI})\end{array}$ & $\begin{array}{l}\text { Adjusted odds ratio } \\
(95 \% \mathrm{CI})\end{array}$ \\
\hline \multicolumn{4}{|c|}{ Main Source of Income } \\
\hline None & $102(19.7)$ & $0.21(3.25-5.50)^{* * *}$ & $0.96(3.21-8.27)^{3 . *}$ \\
\hline Farming & $202(39.1)$ & $0.33(5.41-8.13)^{* * *}$ & $0.37(7.32-6.74)^{* *}$ \\
\hline Self-employed & $140(27.1)$ & 1.00 & 1.00 \\
\hline Salaried & $73(14.1)$ & 1.00 & 1.00 \\
\hline \multicolumn{4}{|c|}{ Level of education completed } \\
\hline None & $7(1.4)$ & 1.00 & 1.00 \\
\hline Primary & $331(64.0)$ & 1.00 & 1.00 \\
\hline Secondary & $166(32.1)$ & $3.23(3.15-6.51)^{* *}$ & $2.62(4.33-4.58)^{* * *}$ \\
\hline Tertiary & $13(2.5)$ & $2.05(3.25-4.50)^{* *}$ & $1.43(2.87-4.63)^{* *}$ \\
\hline \multicolumn{4}{|c|}{$\begin{array}{l}\text { Husbands / Partners } \\
\text { Education }\end{array}$} \\
\hline None & $100(19.3)$ & $0.91(3.97-4.23)^{*}$ & $0.12(4.23-2.59)^{*}$ \\
\hline Primary & $238(46.0)$ & $0.13(3.84-3.62)$ & $0.89(2.07-1.60)^{* *}$ \\
\hline Secondary & $160(30.9)$ & 1.00 & 1.00 \\
\hline Tertiary & $19(3.7)$ & 1.00 & 1.00 \\
\hline \multicolumn{4}{|c|}{ Means of transport to facility } \\
\hline Walked & $296(57.3)$ & $0.33(2.94-3.41)^{*}$ & $0.91(1.62-2.88)^{*}$ \\
\hline Bicycle & $25(4.8)$ & $0.67(1.21-2.60)^{*}$ & $0.84(1.69-2.02)^{*}$ \\
\hline Motorbike & $193(37.3)$ & 1.00 & 1.00 \\
\hline Private car & $3(0.6)$ & 1.00 & 1.00 \\
\hline
\end{tabular}

\section{Maternal healthcare continuum:-}

On the continuum of care situation, Table 4 below shows that the majority of the mothers $438(84.7 \%)$ had a CHV attached to their household. In addition, out of the $438(84.7 \%)$ of the mothers who had a CHV attached to their household, only 119 (23\%) of the mothers had been referred to the health facility by a CHV for pregnancy related care. In addition, all the mothers who participated in this study had no book/document in their household where health services provided by the CHVs or other providers who visit the household were recorded or referred to for continuum of care purposes. In addition, $434(83.9 \%)$ of the mothers had the opportunity of being visited in their households by other health providers other than the CHV. However, only $6.4 \%$ received pregnancy related services from these providers.

Table 4:- Continuum of care

\begin{tabular}{|l|l|l|}
\hline Characteristics & Yes, n (\%) & No, n (\%) \\
\hline Do you have a CHV attached to your HH? & $438(84.7)$ & $79(15.3)$ \\
\hline $\begin{array}{l}\text { Were you ever referred to the health facility by a CHV in your last } \\
\text { pregnancy? } \\
\text { If Yes, For what purpose }\end{array}$ & $119(23.0)$ & $398(77.0)$ \\
\hline Pregnancy related care & $14(12.0)$ & $105(88.0)$ \\
\hline Immunization services & $14(12.0)$ & $105(88.0)$ \\
\hline Curative services & $14(12.0)$ & $105(88.0)$ \\
\hline Family Planning, Eye Care, Cervical cancer screening & $77(64.7)$ & $42(35.3)$ \\
\hline $\begin{array}{l}\text { Are there any book/ document in your household where services } \\
\text { provided by the CHVs are usually recorded? }\end{array}$ & 0 & $517(100.0)$ \\
\hline $\begin{array}{l}\text { Are there health providers who have visited your household in the } \\
\text { past, other than the CHV? }\end{array}$ & $434(83.9)$ & $83(16.1)$ \\
\hline If Yes, For what purpose? & & \\
\hline Pregnancy related services & $28(6.4)$ & $386(93.6)$ \\
\hline Health promotion & $59(13.5)$ & $375(86.5)$ \\
\hline HIV Counseling and testing & $65(15.0)$ & $369(965.0)$ \\
\hline National immunization days & $329(75.8)$ & $105(24.2)$ \\
\hline Malaria testing and treatment & $28(6.4)$ & $406(93.6)$ \\
\hline Net distribution & $66(15.1)$ & $368(84.9)$ \\
\hline
\end{tabular}


The strategies outlined in the framework below were implemented for a period of twelve months with intensive follow up after which an evaluation was carried out and results shown below.

\section{Phase 2:-}

Developed context specific framework;-

The development of the piloted integrated framework was informed by both the baseline findings and the suggestions from the users and maternal healthcare providers. The proposed strategies for increasing utilization of skilled maternal healthcare services were fed into the design of the framework. The framework took into considerations those interventions that target both the supply and demand side barriers to utilization of skilled maternal healthcare services. Included are also suggestions made by key informants and focus group discussants within the selected study sites. The framework contains six prioritized interventions which are interconnected. In line with the available structures, six strategic areas for enhancing maternal healthcare continuum and optimizing utilization of skilled maternal healthcare services were identified by the study and evaluated. They include 1) use of maternal health job aids for guidance at the health facility and community, 2) mother baby booklet, 3) use of referral tools, 4) empowering $\mathrm{CHVs}$ to educate the women and provide basic community maternal healthcare services 5) testing for pregnancy at the community/household level and 6) availing documentation tool at the households for reference and care continuum.

The framework explicitly defined how one intervention informs the other and the feedback mechanism. The interventions were addressing both community and facility bottlenecks which included: Increasing women's awareness on importance of maternal health; Availing 24 skilled delivery services at the health facilities; Improving the quality of interaction between healthcare providers and community; Strengthening community - facility linkage by use of a household log book to document health services provided ; Empowering community health volunteers to educate women and provide community maternal healthcare services and pregnancy testing services at the household to enhance early identification of pregnant women for early initiation of antenatal care, and use of antenatal and postnatal care job aids both the health facilities and community health workers as shown in Table below:-

Table 1:- Framework for increasing utilization of skilled maternal healthcare services

\begin{tabular}{|c|c|c|c|}
\hline Strategy & Justification & $\begin{array}{l}\text { Key findings that support } \\
\text { the strategy }\end{array}$ & $\begin{array}{l}\text { Recommendations for } \\
\text { service delivery (practice) }\end{array}$ \\
\hline $\begin{array}{l}\text { (1) Increasing } \\
\text { women's } \\
\text { awareness on } \\
\text { available maternal } \\
\text { health services and } \\
\text { danger signs }\end{array}$ & $\begin{array}{l}\text { i)Studies have shown that } \\
\text { one of the major barriers to } \\
\text { utilization of skilled maternal } \\
\text { healthcare service is lack of } \\
\text { awareness of the available and } \\
\text { importance of skilled maternal } \\
\text { health services (Mpembeni, } \\
\text { 2007; Tsawe,2014) }\end{array}$ & $\begin{array}{l}\text { i) Baseline findings showed } \\
\text { that only } 34.6 \% \text { of the } \\
\text { women in the study had } \\
\text { adequate knowledge on } \\
\text { available maternal health } \\
\text { while } 55.9 \% \text { had adequate } \\
\text { information on maternal } \\
\text { health danger signs. } \\
\text { ii) Baseline findings also } \\
\text { revealed that } 83.9 \% \text { of } \\
\text { pregnant women had had } \\
\text { the opportunity of being } \\
\text { visited at their households } \\
\text { by other health providers } \\
\text { other than the CHVs to offer } \\
\text { other services not pregnancy } \\
\text { related. This is an indication } \\
\text { that opportunities exist that } \\
\text { could be used to disseminate } \\
\text { maternal health information } \\
\text { by integrating the services } \\
\text { during the household visits. }\end{array}$ & $\begin{array}{l}\text { i)Every opportunity that } \\
\text { either a skilled provider or a } \\
\text { community health worker } \\
\text { interact with the women } \\
\text { should be used for education } \\
\text { and review of women's } \\
\text { understanding of maternal } \\
\text { health. } \\
\text { ii) Women should } \\
\text { continuously be given } \\
\text { information on maternal } \\
\text { health and treated with } \\
\text { respect so as to reduce fears } \\
\text { and increase the uptake of } \\
\text { skilled maternal healthcare } \\
\text { services. } \\
\text { (iii) Every health provider } \\
\text { who visits a household } \\
\text { having a woman of } \\
\text { reproductive health is } \\
\text { encouraged to provide } \\
\text { information on importance of } \\
\text { skilled maternal health } \\
\text { services. }\end{array}$ \\
\hline $\begin{array}{l}\text { (2) Improving } \\
\text { quality of }\end{array}$ & $\begin{array}{l}\text { i) Cases of missed } \\
\text { opportunities exist as evident }\end{array}$ & $\begin{array}{l}\text { (i) Previous studies in Siaya } \\
\text { County revealed that quality }\end{array}$ & $\begin{array}{l}\text { (i) Train providers on } \\
\text { respectful maternity care }\end{array}$ \\
\hline
\end{tabular}




\begin{tabular}{|c|c|c|c|}
\hline $\begin{array}{l}\text { providers and } \\
\text { users interaction } \\
\text { and positive } \\
\text { attitude change }\end{array}$ & $\begin{array}{l}\text { in the DHIS, } 2004 \text { data that } \\
\text { shows that whereas } 82 \% \text { of } \\
\text { women attend first antenatal } \\
\text { care visits, only } 45 \% \text { attend } 4^{\text {th }} \\
\text { antenatal care visits and } 52 \% \\
\text { receive skilled delivery } \\
\text { services. }\end{array}$ & $\begin{array}{l}\text { of interaction between } \\
\text { provider and pregnant } \\
\text { women was poor as women } \\
\text { had vague information } \\
\text { about services offered even } \\
\text { after interacting with skilled } \\
\text { providers (Pell C, 2011) } \\
\text { (ii) Baseline findings } \\
\text { revealed that although } \\
84.9 \% \text { of the women } \\
\text { received antenatal care, only } \\
55.7 \% \text { and } 23.6 \% \text { received } \\
\text { skilled delivery and } \\
\text { postnatal care respectively. }\end{array}$ & $\begin{array}{l}\text { (ii) Promote use of antenatal } \\
\text { and post natal job aids to } \\
\text { enhance quality interaction. } \\
\text { iv) Efforts should be made to } \\
\text { enhance maternal healthcare } \\
\text { continuum by strengthening } \\
\text { community-facility linkage } \\
\text { by ensuring there is effective } \\
\text { communication between the } \\
\text { skilled provider and the } \\
\text { community health volunteer.( } \\
\text { Documentation in the mother } \\
\text { baby book to be strengthened } \\
\text { as part of communication } \\
\text { enhancement). }\end{array}$ \\
\hline $\begin{array}{l}\text { (3) Introducing the } \\
\text { use of a household } \\
\text { log book for } \\
\text { documentation of } \\
\text { all health services } \\
\text { provided at the } \\
\text { household level } \\
\text { (Strengthening } \\
\text { community - } \\
\text { facility linkage) }\end{array}$ & $\begin{array}{l}\text { (i) There has not been any tool } \\
\text { at the household level where } \\
\text { services provided at the } \\
\text { household are documented } \\
\text { thus different providers who } \\
\text { visit the household have no } \\
\text { reference document for } \\
\text { enhancing care continuum and } \\
\text { also ascertaining which } \\
\text { services have been offered at } \\
\text { the household has been a } \\
\text { challenge. }\end{array}$ & $\begin{array}{l}\text { i) Reports indicate that all } \\
(100 \%) \text { of households in } \\
\text { Siaya County have a CHV } \\
\text { who visits on monthly basis } \\
\text { and who is paid stipend by } \\
\text { the County government. } \\
\text { However, baseline findings } \\
\text { revealed that } 15.3 \% \text { of the } \\
\text { households had never been } \\
\text { visited by a CHV which is } \\
\text { an indication that some } \\
\text { CHVs do not carry out their } \\
\text { mandate. }\end{array}$ & $\begin{array}{l}\text { i) Development, sensitization } \\
\text { of providers, community and } \\
\text { the mothers, and distribution } \\
\text { of a household health visitors } \\
\text { log book for documentation } \\
\text { of all services provided at the } \\
\text { household level and for } \\
\text { reference. } \\
\text { ii) Provide referral tools to all } \\
\text { CHVs and provide space for } \\
\text { skilled provider's comments } \\
\text { and assignment to CHVs in } \\
\text { the mother baby booklet. }\end{array}$ \\
\hline $\begin{array}{l}\text { (4) Empowering } \\
\text { community health } \\
\text { volunteers with } \\
\text { knowledge on } \\
\text { maternal health } \\
\text { and danger signs }\end{array}$ & $\begin{array}{l}\text { (i) The majority of the CHVs } \\
\text { have not been trained on } \\
\text { maternal healthcare and } \\
\text { therefore they may not be } \\
\text { confident to share the } \\
\text { information with the } \\
\text { mothers/women during } \\
\text { household visits. }\end{array}$ & $\begin{array}{l}\text { (i) Baseline findings } \\
\text { revealed maternal health } \\
\text { knowledge gap amongst the } \\
\text { study participants which } \\
\text { may be attributed to lack of } \\
\text { opportunities for education } \\
\text { on maternal health. }\end{array}$ & $\begin{array}{l}\text { i) Training of CHVs on } \\
\text { Community maternal health. } \\
\text { ii) Development and } \\
\text { promotion of use of antenatal } \\
\text { and postnatal care job aids to } \\
\text { guide CHVs when providing } \\
\text { maternal health education. }\end{array}$ \\
\hline
\end{tabular}

Phase 3:- Evaluation of the effectiveness of the framework

End line results have indicated that the majority of the mothers at $468(92.3 \%), 328(64.6 \%)$ and 241(47.4) received Antenatal care (ANC), Skilled delivery and postnatal care respectively compared to the baseline where mothers who received maternal healthcare services were $439(84.9 \%), 288(55.7 \%)$ and $122(23.6 \%)$ respectively. The findings imply that after intervention, more mothers received skilled maternal healthcare services at the various health facilities in Siaya County. 
Figure 1:- Utilization of skilled maternal health care services

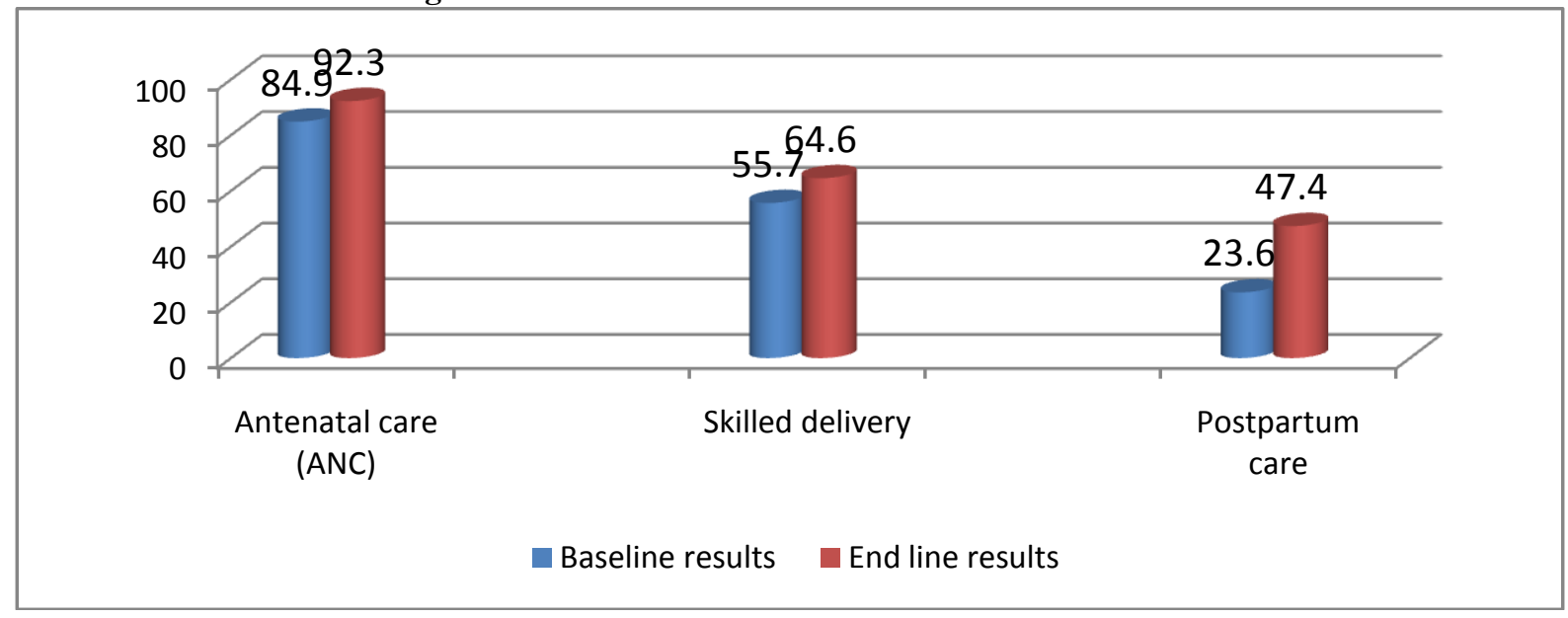

The results below indicate that the number who utilized the recommended 4 antenatal care visits or more $(\geq 4)$ at end line increased by $18 \%$, an indication that the framework was effective in increasing uptake of skilled maternal health services.

Figure 2:- Utilization of skilled maternal healthcare services Vs Antenatal care services received at Baseline and at End line

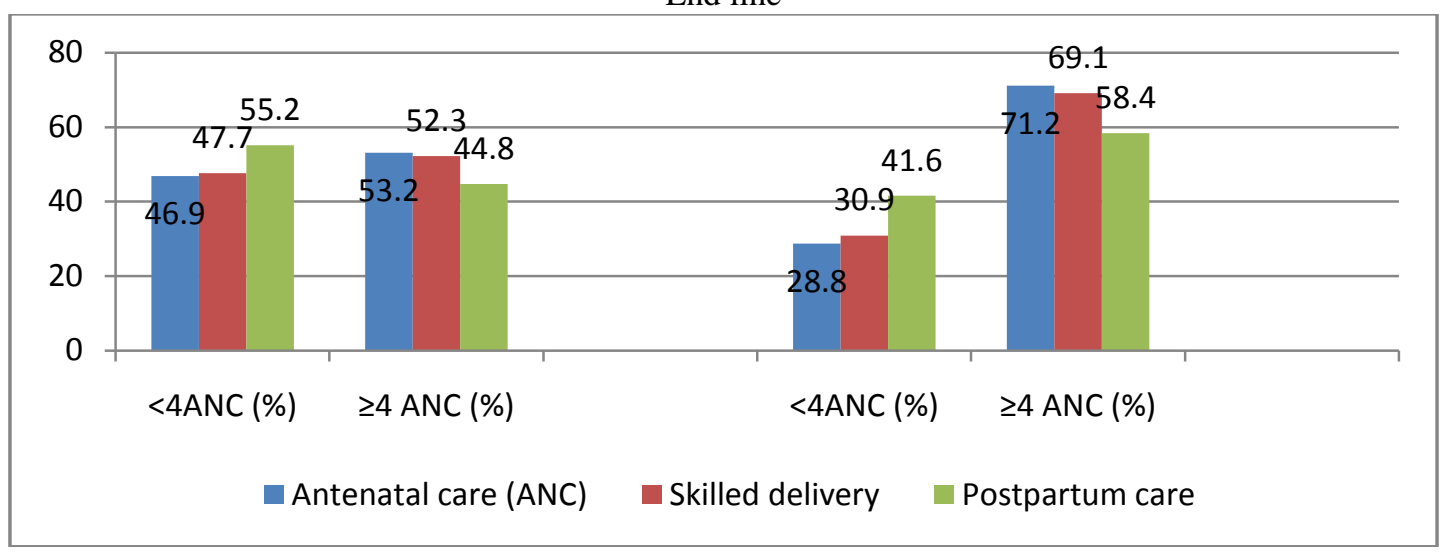

Compared to the baseline where only 179 (34.6\%) mothers had adequate knowledge on maternal health; intervention findings revealed that $321(63.2 \%)$ had adequate knowledge on available skilled maternal health services. In addition, those who utilized $\geq 4$ ANC visits increased from $58.7 \%$ to $63.9 \%$. Moreover, those who had knowledge on maternal healthcare danger signs also increased from 289 (55.9) to 418 (82.3) with an increase from $62.4 \%$ to $78.8 \%$ amongst those who took up $\geq 4$ ANC visits. The findings revealed highly significant positive relationship between knowledge on availability of skilled maternal healthcare services, knowledge on maternal danger signs and number of antenatal care services received ( $\mathrm{p}<0.04$ and $p<0.002$ respectively).

Table 2:- Knowledge on maternal health services (MHS) Vs Antenatal care (ANC) services received at Baseline and at End line

\begin{tabular}{|c|c|c|c|c|c|c|c|c|}
\hline & \multicolumn{4}{|c|}{ Baseline results } & \multicolumn{4}{|c|}{ End line results } \\
\hline Variables & $\begin{array}{l}\text { Total, n } \\
(\%)\end{array}$ & $\begin{array}{l}<4 \mathrm{ANC} \\
(\%)\end{array}$ & $\begin{array}{l}\geq 4 \mathrm{ANC} \\
(\%)\end{array}$ & $\begin{array}{l}\mathbf{P} \\
\text { value }\end{array}$ & $\begin{array}{l}\text { Total, } n \\
(\%)\end{array}$ & $\begin{array}{l}<4 \mathrm{ANC} \\
(\%)\end{array}$ & $\begin{array}{l}\geq 4 \text { ANC } \\
(\%)\end{array}$ & $\begin{array}{l}\mathbf{P} \\
\text { value }\end{array}$ \\
\hline \multicolumn{4}{|c|}{ Knowledge on available MHS services } & 0.007 & & & & 0.004 \\
\hline Adequate & $179(34.6)$ & 41.3 & 58.7 & & $321(63.2)$ & 36.1 & 63.9 & \\
\hline Inadequate & $338(65.4)$ & 58.1 & 41.9 & & $187(36.8)$ & 52.8 & 47.2 & \\
\hline \multicolumn{4}{|c|}{ Knowledge of maternal danger signs } & 0.001 & & & & 0.002 \\
\hline Yes & $289(55.9)$ & 37.6 & 62.4 & & $418(82.3)$ & 21.2 & 78.8 & \\
\hline No & $228(44.1)$ & 62.8 & 37.2 & & $90(17.7)$ & 49.0 & 51.0 & \\
\hline
\end{tabular}




\section{The findings on the maternal healthcare continuum situation:-}

On the continuum of care situation among the mothers, the researcher designed a questionnaire to collect views of the respondents on the same. The mothers' respondents were presented with statements that had continuum of care situation connotations with different answering techniques. The researcher computed percentage frequencies of the responses from the mothers and was tabulated as shown in the table 3 shown.

Table 3:- Continuum of care situation

\begin{tabular}{|l|l|l|l|l|}
\hline \multicolumn{2}{|c|}{ Baseline results } & \multicolumn{2}{l|}{ End line results } \\
\hline Variables & Yes, N (\%) & No, N (\%) & Yes, N (\%) & No, N (\%) \\
\hline Do you have a CHV attached to your HH? & $438(84.7)$ & $79(15.3)$ & $475(93.5)$ & $33(6.5)$ \\
\hline $\begin{array}{l}\text { Were there services (MHS) offered to you at } \\
\text { home during the time you were pregnant? }\end{array}$ & $376(72.7)$ & $14127.3)$ & $408(80.3)$ & $100(19.7)$ \\
\hline $\begin{array}{l}\text { Are there any book/ document in your } \\
\text { household where services provided by the } \\
\text { CHVs are usually recorded? }\end{array}$ & - & $517(100.0)$ & $414(81.6)$ & $94(18.4)$ \\
\hline
\end{tabular}

The descriptive statistics on cross tabulations indicates that the number of mothers with CHWs attached to their households in Siaya County increased from $438(84.7 \%)$ to $475(93.5 \%)$ during the end line. However, 33 (6.5\%) of the mothers still did not have any CHV attached to their household at end line compared to $79(15.3 \%)$ at baseline as indicated in Siaya County 2014-15 performance report. Of note, compared to baseline, the number of households with health visitor's documentation booklets increased from $0 \%$ at baseline to $81.6 \%$ at end line

\section{Discussion:-}

The results of this study show that the context specific framework was effective in increasing utilization of skilled maternal healthcare services in Siaya County. Whereas at baseline, those who received at least one antenatal care visit were $84.9 \%$, skilled delivery were $55.7 \%$ while only $23.6 \%$ received post-natal care within 48 hours of delivery, at end line antenatal care (ANC) increased to $468(92.3 \%)$, skilled delivery to $328(64.6 \%)$ and postnatal care to 241(47.4) respectively. The baseline findings were consistent with data in DHIS which reflected low utilization of skilled maternal healthcare services in Siaya County (www.hiskenya.org). Of note was that compared to baseline where only $53.2 \%$ received the WHO recommended $\geq 4$ ANC visits, at end line $71.2 \%$ received $\geq 4$ antenatal care visits. The above findings are similar to findings from previous studies which revealed that knowledge on maternal health, awareness of importance of maternal healthcare services, knowledge on danger signs and enhanced continuum of care can increase utilization of skilled maternal healthcare services (Jerome, Per-Olof, Eleanor, \& Karen, 2011; Mwangome, Holding, Songola, \& Bomu, 2012; Pembe et al., 2009; Shahram, Hamajima, $\&$ Reyer, 2015; Stevens, 2000).

Similar to previous studies that showed that utilization of skilled maternal healthcare services is influenced by a multiplicity of factors including economic status of the mother, mothers education, husbands income, husbands education and distance to health facility/ transport costs (Deo KK, 2015; Doku, Neupane, \& Doku, 2012; Idris, Sambo, \& Ibrahim, 2013; KC et al., 2011; Malhotra, 2014; Siddharudha Shivalli, 2015; Titaley, Dibley, \& Roberts, 2009), the findings of this study showed that participants with no source of income (aOR=0.96, 95\% CI: $3.21-8.27$ ) and those who were farmers ( $\mathrm{aOR}=0.37,95 \% \mathrm{CI}$ : 7.32-6.74) were less likely to utilize maternal healthcare services relative to traders/self-employed and salaried. Women with secondary ( $\mathrm{aOR}=2.62,95 \% \mathrm{CI}$ : $4.33-4.58)$ and tertiary (aOR=1.43, 95\% CI: 2.87-4.63) education were more likely to utilize maternal healthcare services relative to those with no education and those with primary education. Similarly, women whose husbands had no education $(\mathrm{aOR}=0.89,95 \%$ CI: $2.07-1.60)$ or had primary education (aOR=0.89, 95\% CI: $2.07-1.60)$ were less likely to utilize maternal healthcare services relative to those whose husbands had secondary or tertiary level of education. In consistent with other studies, the findings of this study also revealed that means of transport/ means of reaching the facility had effect on utilization of skilled maternal healthcare services ( Kawakatsu. et al, 2012; Worku et al, 2013; Ayele et al, 2014). Those who walked $(\mathrm{aOR}=0.91(1.62-2.88)$ or used bicycle $(\mathrm{aOR}=0.84$ (1.69-2.02) were also less likely to utilize skilled maternal health services compared to those who used motorbike or private car.

The findings corroborate with previous studies, that knowledge on available skilled maternal health services and knowledge on maternal health danger signs is associated with utilization of skilled maternal healthcare services ((Jerome et al., 2011; Mwangome et al., 2012; Pembe et al., 2009; Shahram et al., 2015; Stevens, 2000), this study 
showed that at baseline when only $36.4 \%$ had adequate knowledge on importance of skilled maternal healthcare while $55.9 \%$ adequately knew the maternal danger signs; utilization of skilled maternal healthcare services was also low. Whereas at end line where $63.2 \%$ of participants had adequate knowledge on importance of skilled maternal healthcare; utilization of skilled maternal healthcare services increased.

Although it is acknowledged that community-level interventions are potentially effective ways to address the problem at its roots, as decisions to seek and access health care are strongly influenced by the socio-cultural environment (Lawn et al., 2005; John et al., 1998) and that Saving lives depends not only on high coverage but also on the quality of care delivered through the continuum (PNMCH, 2010; Portela et al., 2003), the baseline findings showed that contrary to reports in Siaya County which shows that all households receive CHV services in Siaya County (Siaya County health department performance review report (2014/15), some households (15.3\%) had never been visited by a community health volunteer at all. This is an indication of disconnect in the continuum of care (Siaya County health department performance review report (2014/15). However, at end line, the results showed some improvement although $6.5 \%$ still did not have an opportunity to be visited by a CHV despite the emphasis that all be followed up. More puzzling was the finding at baseline that, there was no $(0 \%)$ book/document/evidence in all the households where services provided by the CHVs and other health providers were recorded or could be referred to for continuum of care purposes. However, at end line after intervening, the majority $(81.6 \%)$ had the household booklets for documentation of all heath services provided at the households. The context specific framework was found to be suitable for increasing utilization of skilled maternal healthcare services. However there is still room to further refine it to include other strategies proposed by previous scholars.

The implications of these findings are that each strategy contributes some percentage increase in utilization of skilled, maternal health care services. Therefore integration of several strategies brings synergy and yields better results. The context specific framework should be considered for programming towards increasing utilization of skilled maternal healthcare services.

\section{Conclusion:-}

Based on the findings of the longitudinal study carried out between March 2015 and December 2015, it is evident that no single intervention is by itself sufficient to increase utilization of skilled maternal healthcare services. Context specific, evidence based framework maximizes the benefits of a range of interventions which complement each other resulting in enhanced continuum of care and increased utilization of skilled maternal healthcare services.

Declarations

\section{Acknowledgements:-}

Authors would like to acknowledge Department of Health, Siaya County, Skilled health providers and community Health workers in Siaya County, Research assistants, and all the participants who participated in this study.

\section{Ethical considerations:-}

Ethical clearance was obtained from Research Ethics Committee of University of Eastern Africa, Baraton, Eldoret (REC: UEAB /05/02/2015). The research assistants were trained on research ethics. Informed written consent from the study participants was obtained and the objective of the study was explained to them. Privacy and confidentiality of collected information was ensured at all levels.

\section{Consent to publish:-}

Consent to publish was obtained from Research Ethics Committee of University of Eastern Africa, Baraton, Eldoret (REC: UEAB /05/02/2015).

\section{Competing interests:-}

The authors declare that there are no competing interests.

\section{Funding;-}

This work was supported by kind contributions from friends.

\section{Author Contributions:-}

OEO conceptualized the paper, searched literature, and wrote the manuscript draft. ASO contributed to the design of the study and provided advice regarding data interpretation. FAA helped develop the data analysis framework and 
also helped train field researchers for data collection. OEO and ASO analyzed the qualitative data. AK made critical revisions to the paper and provided advice regarding data interpretation. OSO participated in data collection and helped write the results and discussion sections. All authors read and approved the final manuscript.

\section{Author details;-}

Department of Public Health, School of Health Sciences, Jaramogi Oginga Odinga University of Science and Technology ${ }^{1}$; Department of Biological Sciences, School of Biological and Physical Sciences, Jaramogi Oginga Odinga University of Science and Technology ${ }^{2}$; Department of Health, County Government of Siaya ${ }^{3}$

\section{References:-}

1. Bourbonnais, N. (2013). Implementing Free Maternal Health Care in Kenya: Challenges, Strategies, and Recommendations.

2. Deo KK, P. Y., Khatri RB,Bhaskar RK, Paudel R, Mehata S and Wagle RR (2015). Barriers to utilization of antenatal care services in eastern Nepal. Front. Public Health 3:197. Doku, D., Neupane, S., \&

3. Doku, P. (2012). Factors associated with reproductive health care utilization among Ghanaian women. BMC Int Health Hum Rights, 12. doi: 10.1186/1472-698x-12-29

4. Gilmore B, M. E. (2013). Effectiveness of community health workers delivering preventive interventions for maternal and child health in low- and middle-income countries: a systematic review. BMC Public Health, 13: (847) ). doi: doi:10.1186/1471-2458-13-847.

5. Glenton C, C. C., Carlsen B, Swartz A, Lewin S, Noyes J, Rashidian A. Cochrane Database Syst Rev. . (2013). Barriers and facilitators to the implementation of lay health worker programmes to improve access to maternal and child health: qualitative evidence synthesis.

6. Graham, L., Moodley, J., \& Selipsky, L. (2012). The disability-poverty nexus and the case for a capabilities approach: evidence from Johannesburg, South Africa. Disability \& Society. International Journal on poverty index, 28(3), 324-337.

7. Health, M. o. (2006). Taking the Kenya Essential Package for Health to the Community: A Strategy for the Delivery of LEVEL ONE SERVICES.Health, M. o. (2014). Kenya Health Policy.

8. Idris, S., Sambo, M., \& Ibrahim, M. (2013). Barriers to utilisation of maternal health services in a semi-urban community in northern Nigeria: The clients' perspective. Nigerian Medical Journal, 54(1), 27-32. doi: 10.4103/0300-1652.108890

9. Jerome, K. K., Per-Olof, O., Eleanor, T., \& Karen, O. P. (2011). Knowledge of obstetric danger signs and birth preparedness practices among women in rural Uganda.

10. KC, A., Bhandari, N., Pradhan, Y., KC, N., Upreti, S., Thapa, K., . . Dhakwa, J. (2011). State of maternal, newborn and child health programmes in Nepal: what may a continuum of care model mean for more effective and efficient service delivery? J Nepal Health Res Council, 9.

11. Kenya, M. G. (2010). Taking the Kenya Essential Package for Health. . Kenya.

12. Kenya, M. o. H.-. (2012). Maternal and Child Health Status in Kenya

13. Kenya National Bureau of Statistics, Ministry of Health/Kenya, National AIDS Control Council/Kenya, Kenya Medical Research Institute, Population, N. C. f., \& Development/Kenya. (2015a). Kenya Demographic and Health Survey 2014. Rockville, MD, USA.

14. Kenya National Bureau of Statistics, Ministry of Health/Kenya, National AIDS Control Council/Kenya, Kenya Medical Research Institute, Population, N. C. f., \& Development/Kenya. (2015b). Kenya Demographic and Health Survey 2014. Rockville, MD, USA: Retrieved from http://dhsprogram.com/pubs/pdf/FR308/FR308.pdf.

15. KNBS. (2009). Kenya National Bureau of Statistics (KNBS), ICF Macro. 2010. Kenya. Demographic and Health Survey 2008-2009. Calverton, Maryland: KNBS, ICF Macro.

16. Lewin S, M.-B. S., Glenton C, Daniels K, Bosch-Capblanch X, van Wyk BE, Odgaard-Jensen J, Johansen M, Aja GN, Zwarenstein M, Scheel IB. . (2010). Lay health workers in primary and community health care for maternal and child health and the management of infectious diseases. Cochrane Database Syst Rev. . PubMed.

17. Macro, K. N. B. o. S. K. a. I. (2010). Kenya Demographic and Health Survey 2008-09 DHS Final Reports. Nairobi, Kenya.

18. Malhotra, C., Malhotra, R., Ostbye, T., \& Subramanian, S. V. . (2014). Maternal autonomy and child health care utilization in India: results from the National Family Health Survey. . Asia Pac J Public Health.,, 26(4), 401-413. . doi: 10.1177/1010539511420418. .

19. MOH. (2010). Ministry of Health (MOH) [Kenya]. 2010b. The national health sector strategic plan. Nairobi: $\mathrm{MOH}$. 
20. Mwangome, F. K., Holding, P. A., Songola, K. M., \& Bomu, G. K. (2012). Barriers to hospital delivery in a rural setting in Coast Province, Kenya: community attitude and behaviours. . Rural Remote Health., 12(1), 1852-1855.

21. Pell C, M. A., Were F, Afrah NA, Chatio S, et al. (2013). Factors Affecting Antenatal Care Attendance. PLoS ONE, 8(1).

22. Pell C, M. A., Were F, Afrah NA, Chatio S, Manda-Taylor L, et al. (2013) (2013). Factors Affecting Antenatal Care Attendance: Results from Qualitative Studies in Ghana, Kenya and Malawi. . PLoS ONE, 8((1): e53747). doi: 10.1371/journal.pone.0053747

23. Pembe, A. B., Urassa, D. P., Carlstedt, A., Lindmark, G., Nystrom, L., \& Darj, E. (2009). Rural Tanzanian women's awareness of danger signs of obstetric complications. . BMC Pregnancy Childbirth, 12(10), 14711482.

24. Kenya Human Rights Commission (2012). Access to electricity in Kenya: Enabling the realization of human rights. Nairobi: KNCHR.

25. Shahram, M. S., Hamajima, N., \& Reyer, J. A. (2015). Factors affecting maternal healthcare utilization in Afghanistan: secondary analysis of Afghanistan Health Survey. Nagoya Journal of Medical Science., 77(4), 595-607.

26. Siaya, C. G. o. (2013). Siaya County health department performance report, 2013/14.

27. Siddharudha Shivalli, a. S. K. (2015). "Comment on "The Prevalence of Skilled Birth Attendant Utilization and Its Correlates in North West Ethiopia",". BioMed Research International,, vol. 2015, , 1-2.

28. Simkhada B, V. T. E. R., Porter M, Simkhada P. . (2008). Factors affecting the utilization of antenatal care in developing countries: systematic review of the literature. . J Adv Nurs., 61, 244-260.

29. Starrs, A. M. (2006). Safe motherhood initiative: 20 years and counting. The Lancet, 368(9542), 1130-1132. doi: 10.1016/S0140-6736(06)69385-9

30. Statistics, K. N. B. o. (2013). Nyanza Province Multiple Indicator Cluster Survey 2011, Final Report. Nairobi, Kenya:: Kenya National Bureau of Statistics

31. Stevens, R. D. (2000). Safe motherhood: an insight into maternal mortality in the developing world. . Health Millions., 26(3), 34-37.

32. Titaley, C., Dibley, M., \& Roberts, C. (2009). Factors associated with non-utilisation of postnatal care services in Indonesia. J Epidemiol Community Health, 63. doi: 10.1136/jech.2008.081604

33. UNICEF, S. C. H. M. T. (2013). Siaya Investment Case for Maternal and Child Health (S. C. H. Department, Trans.). Siaya County: County Government.

34. Villar, J., Ba'aqeel, H., Piaggio, G., Lumbiganon, P., Miguel Belizán, J., Farnot, U., . . Garcia, J. (2001). WHO antenatal care randomised trial for the evaluation of a new model of routine antenatal care. Lancet, 357(9268), 551-564.

35. Wang, Makela, S., Lopez, A., Lozano, R. M., Hogan, M., Foreman, K., . . . Ahn, S. C. (2010). Maternal mortality for 181 countries, 1980-2008: asystematic analysis of progress towards Millennium Development Goal. Lancet, 375(9726), 1609-1623.

36. Wang, W., Hong, Rathavuth. (2015). Levels and determinants of continuum of care for maternal and newborn health in Cambodia-evidence from a population-based survey. BMC Pregnancy and Childbirth, 15(1), 62. doi: 10.1186/s12884-015-0497-0

37. WHO. (2011). The Partnership for Maternal, Newborn \& Child Health. Analysing Commitments to Advance the Global Strategy for Women's and Children's Health. The PMNCH 2011 Report. Geneva, Switzerland: PMNCH.

38. WHO. (2012). WHO, UNICEF. Countdown to 2015 maternal, newborn and child survival: building a future for women and children. Washington DC: World Health Organization and UNICEF.

39. WHO. (2014). recommendations on Postnatal care of the mother and newborn

40. WHO, ICM, \& FIGO. (2004). World Health Organization: Making pregnancy safer: The critical role of the skilled attendant by WHO, ICM and FIGO. World Health Organization.

41. WHO, U., UNFPA, WORLD BANK. (2012). World Health Organization, "Trends in maternal mortality: 1990 to 2010. WHO, UNICEF, UNFPA and The World Bank Estimates, . Genava, Switzerland.

42. WHO, U., UNFPA, The World Bank and the United Nations Population Division. (2014). Trends in maternal mortality: 1990 to 2013. Estimates (pp. 56). Geneva.

43. WHO, U., UNFPA, The World Bank and the United Nations Population Division. (2014). Trends in Maternal Mortality: $1990-2013$.

44. www.hiskenya.org, D. (2013/14). District Health Information Software. 
45. Yeboah-Antwi, K., Hamer, D. H., Semrau, K., Waltensperger, K. Z., Snetro-Plewman, G., Kambikambi, C., . Marsh, D. R. (2014). Can a community health worker and a trained traditional birth attendant work as a team to deliver child health interventions in rural Zambia? BMC Health Services Research, 14(1), 516. doi: 10.1186/s12913-014-0516-2

46. Zohra, S., Lassi, A., Philippa, F., Middleton, A., Caroline, C. A. B., Zulfiqar, A., \& Bhuttac, D. (2015). Interventions to Improve Neonatal Health and Later Survival: An Overview of Systematic Reviews. EBioMedicine, 2(8), 985-1000. 